\title{
ROLE OF CT IN ASSESSMENT OF BLUNT CHEST TRAUMA
}

By

\begin{abstract}
Ahmed Abouzeid Metwally Mohamed Galal, Abd El-Nabi Bayoumi Mohamed and Ahmed Mohamed Abd El-Ghaffar Zidan
\end{abstract}

Department of Radio diagnosis, Faculty of Medicine, Al-Azhar University

Corresponding author: Ahmed Abouzeid Metwally Mohamed Galal, Mobile: (+20) 01017106789, E-mail: mustafatolba@yahoo.com

\begin{abstract}
Background: Blunt chest trauma is a significant problem affecting mainly young males between 20-40 years and it is usually caused by motor vehicle accidents. It is common and contributes significantly to morbidity and mortality of trauma patients. It has an overall fatality rate of $15-25 \%$.

Objective: To evaluate the role of multi-detector computed tomography in assessment of patients with blunt chest trauma.

Patients and Methods: This study involved 50 patients; 40 males (70\%) and 10 females (30\%). Their ages range was 2-75 years (mean age $=51.4$ years). They were exposed to blunt chest trauma and referred to the Emergency Radiology Department in Nasr City Hospital and Al-Azhar University Hospitals for multi detector computed tomography (MDCT) of the chest over a period of 6 months starting from November 2019 to April 2020.

Results: Multi-planner and 3D reconstruction images were sensitive in the evaluation of different skeletal injuries especially dorsal spine, scapular and sternal fractures. Its high resolution provides more sensitivity in the evaluation of lung contusion that helped in predicting the need for mechanical ventilation. MDCT was more accurate and sensitive in the diagnosis and characterization of different types of pleural and mediastinal injuries. Multidetector CT generated virtual bronchoscopy represented one of the most recent developments in three-dimensional (3D) visualization technique which allowed a 3D evaluation of the airways down to the sixth- to seventh-generation. MDCT not only detected small diaphragmatic discontinuities, but also identified the herniated fat or viscera.
\end{abstract}

Conclusion: The information provided by MDCT may lead to critical changes in patients' management, so that clinicians, radiologists, and radiology residents should be familiar with the different aspects of MDCT evaluation of this non-negligible group of patients.

Keywords: Blunt Chest Trauma, CT, MDCT.

\section{INTRODUCTION}

Chest trauma is classified as blunt or penetrating, with blunt trauma being the cause of most thoracic injuries (90\%). The main difference lies in the presence of an opening to the inner thorax in penetrating trauma, created by stabbing or gunshot wounds, which is absent in blunt chest trauma (Mirka et al., 2012).

Penetrating injuries frequently cause pneumothorax or hemothorax and blood loss with cardiac or vascular injuries may be catastrophic. Patients often deteriorate rapidly but with appropriate management, 
have the potential to improve rapidly (Blyth, 2014).

Blunt trauma in addition to pneumothorax and hemothorax typically causes organ damage by compression, acceleration or deceleration and shear forces. In contrast to penetrating trauma, the majority of blunt injuries are managed non-operatively, responding to emergency department interventions such as intubation and ventilation or intercostal drainage (Blyth, 2014).

Imaging studies play an essential part of thoracic trauma care. Chest radiography (CXR) has been the traditional screening technique to evaluate thoracic trauma. However, the information obtained is suboptimal for the diagnosis of vascular and nonvascular thoracic injuries, as it underestimates the severity and extent of chest trauma and, in some cases, fails to detect the presence of injury. There is a growing evidence that multi detector computed tomography (MDCT) is more sensitive than CXR in the detection and characterization of thoracic injuries after trauma (Palas et al., 2014).

MDCT has dramatically decreased imaging times and offers readily available multiplanar reformatted images or more sophisticated volume-rendered and MIP images. Therefore, it has been established as the gold standard for the imaging evaluation of chest trauma and trauma in general (Davies et al., 2016).

The aim of this study was to evaluate the role of multi-detector computed tomography in assessment of patients with blunt chest trauma.

\section{PATIENTS AND METHODS}

This study involved 50 patients; 40 males $(70 \%)$ and 10 females (30\%), their age range was 2-75 years (mean age $=51.4$ years).They were exposed to blunt chest trauma and referred to the emergency radiology department in Nasr city hospital and Al-Azhar University Hospitals for MDCT of the chest over a period of 6 months starting from November 2019 to April 2020.

Inclusion criteria: All cases with blunt chest trauma either as a sole presentation or as a part of poly-traumatic insults were included in this study.

Exclusion criteria: Patients in need of emergency transfer to surgery. Patients who were hemodynamically unstable. Lactating and pregnant females.

An approval of the study was obtained from Al- Azhar University academic and ethical committee. Every patient signed an informed written consent for acceptance of the operation or informed written consents were obtained from relatives of all participants in this study.

\section{All patients were subjected to:}

1. Thorough clinical examination with history taking, general and chest examination.

2. Plain chest X-ray AP (supine) views were done to all patients.

3. CT chest (Table 1 shows the MSCT technique) was done to all patients as requested using 16 channels MSCT. 
Table (1): NECT technique

\begin{tabular}{|c|c|}
\hline & Siemens Emotion 6 MSCT 16 channel \\
\hline Scout & $\begin{array}{c}\text { Kv120 } \\
\mathrm{mA} 25 \\
\text { Holding breath }\end{array}$ \\
\hline Scan type & Helical \\
\hline Detector row & 16 \\
\hline Helical thickness & $1.25 \mathrm{~mm}$ \\
\hline Interval & $1 \mathrm{~cm}$ \\
\hline FOV & $351 \mathrm{~mm}$ from root of the neck to level of renal arteries. \\
\hline KV & 120 \\
\hline mA & 20 \\
\hline Total exposure time & $0.8 \mathrm{sec}$ \\
\hline
\end{tabular}

\section{Statistical analysis:}

Data were fed to the computer and analyzed using IBM SPSS software package version 20.0. Qualitative data were described using number and percent. Quantitative data were described using range (minimum and maximum), mean and standard deviation.

\section{RESULTS}

Out of the 50 patients, $74 \% \quad(n=37$ patients) were males and $26 \% \quad(\mathrm{n}=13$ patients) were females with age ranging from 2-75 years (mean $=51.4$ years) and most of the patients were in the age group $21-50$ years $(n=31$ patients) $(62 \%)$ (Table 2).

Table (2): Number of patients in different age groups

\begin{tabular}{|c|c|}
\hline Age group & Number of patients (\%) \\
\hline $0-10$ & $4(8 \%)$. \\
\hline $11-20$ & $5(10 \%)$. \\
\hline $21-30$ & $9(18 \%)$. \\
\hline $31-40$ & $12(24 \%)$. \\
\hline $41-50$ & $10(20 \%)$. \\
\hline $51-60$ & $5(10 \%)$. \\
\hline $61-70$ & $2(4 \%)$. \\
\hline $71-80$ & $3(6 \%)$. \\
\hline
\end{tabular}

The most common mechanism of blunt chest trauma was as a result of motor vehicle accidents $58 \% \quad(\mathrm{n}=29$ patients $)$ followed by falling from height $36 \%$ ( $\mathrm{n}=18$ patients) then direct blow to chest $6 \%(\mathrm{n}=3$ patients) (Table 3 ).
Endotracheal tube was inserted in 8 patients $(16 \%)$ in the Emergency Department. chest tube placed prior to MDCT scan in 14 patients (28\%). Central venous line and nasogastric feeding tube were inserted in $9(18 \%)$ and $6(12 \%)$ patients respectively (Table 3 ). 
The most common clinical presentations were chest pain $(\mathrm{n}=38$ patients) $(76 \%)$, dyspnea ( $\mathrm{n}=35$ patients) (70\%), local chest tenderness $(n=12$ patients) (24\%) and hemoptysis ( $\mathrm{n}=5$ patients) (10\%); More than one presentation was also encountered in the same patient (Table 3).

Table (3): Mechanism of injury, Intervention done and Clinical presentations in the 50 patients

\begin{tabular}{|l|c|}
\hline Patients & No. (\%) \\
\hline Mechanism of injury: & \\
\hline Motor vehicle accidents & $29(58 \%)$ \\
Falling from height & $18(36 \%)$ \\
Direct blow to the chest & $3(6 \%)$ \\
\hline
\end{tabular}

\begin{tabular}{|l|c|}
\hline Intervention done: & \\
\hline Chest tube & $14(28 \%)$ \\
Central venous line & $9(18 \%)$ \\
Endotracheal tube & $8(16 \%)$ \\
Nasogastric feeding tube & $6(12 \%)$ \\
\hline
\end{tabular}

\begin{tabular}{|l|c|}
\hline Clinical presentations: & \\
\hline Chest pain & $38(76 \%)$ \\
Dyspnea & $35(70 \%)$ \\
Local chest tenderness & $12(24 \%)$ \\
Hemoptysis & $5(10 \%)$ \\
\hline
\end{tabular}

According to side of affection; both sides were affected in 21 patients $(42 \%)$, right side in 17 patients $(34 \%)$ and left side in 12 patients (24\%). Positive radiological findings among patients in order of frequency were pleural injuries in 36 patients $(72 \%)$, parenchymal lung injuries in 30 patients $(60 \%)$, chest wall injuries in 17 patients (34\%), mediastinal injuries in 7 patients (14\%), diaphragmatic injuries in 2 patient (4\%) and finally tracheo-bronchial injuries in 1 patient (2\%) (Table 4).

\section{Out of a total of 50 patients;}

Chest wall injuries were detected in 17 (34\%) patients (Table 4):

\section{Bony chest wall injuries included:}

- Rib fractures were detected in 9 patients $(18 \%)$ (5 cases on right side, 3 cases on left side and 1 case on both sides). It was detected in only one patient at childhood age group. Sternal fracture was detected in 1 patient $(2 \%)$, Clavicular fractures were detected in 2 patients (4\%) both were on the right side and Scapular fractures were detected in 3 patients $(6 \%)$ both were on the right side all fractures at scapular body and not reaching articular surfaces. Dorsal spine fractures were detected in 2 patients $(4 \%)$.

Soft tissue chest wall injuries included:

- Surgical emphysema was detected in 15 patients (30\%) (5 cases on left side, 6 cases on right side and 6 cases on both sides). Chest wall hematoma was detected in 9 patients (18\%) (5 cases on right side, 3 cases on left side and one case on both sides). All cases of chest wall hematomas were related to fractured ribs. 
Pleural space injuries were detected in $36(72 \%)$ patients (Table 4):

Pleural fluid collection were detected in 21 patients $(42 \%)$ (6 cases on left side, 7 cases on right side and 8 cases on both sides). Pneumothorax were detected in 10 patients $(20 \%)$ and they are classified as following: Simple pneumothorax was detected in 7 patients ( 3 cases on left side 2 cases on right side and 2 cases on both sides). Tension pneumothorax was detected in 3 cases ( 1 case on left side and 2 cases on right side). Hydropneumothorax was detected in 5 patients (10\%) (2 cases on left side, 3 cases on right side).

Lung parenchymal injuries were detected in $30(60 \%)$ patients (Table 4):

contusion was detected in 28 patients (56\%) (9 cases on left side, 14 cases on right side and 5 cases on both sides). Lung laceration was detected in 2 patients (4\%).
Mediastinal injuries were detected in 7 (14\%) patients (Table 4):

Pneumo-mediastinum is detected in 5 patients $(10 \%)$. Hemo-pericardium (pericardial collection) is detected in 3 patients $(6 \%)$. Pneumo-pericardium is detected in 2 patients (4\%). Esophageal injuries are suspected in 0 patients $(0 \%)$.

Diaphragmatic injuries were detected in $2(4 \%)$ patients (Table 4$)$ :

Both cases were right sided diaphragmatic herniation.

Tracheo-bronchial injuries were suspected in $2(4 \%)$ patients (Table 4):

One case was partial avulsion of right main bronchus and another case shows complete avulsion of left main bronchus with fallen lung sign noted, both cases are confirmed by three dimensional virtual bronchography.

Table (4): Summary of CT findings in blunt chest trauma

\begin{tabular}{|l|l|c|}
\hline \multicolumn{2}{|c|}{ Cases } & No. (\%) \\
\hline \multirow{4}{*}{ Thoracic wall Injuries } & Rib Fracture & $9(18 \%)$ \\
\cline { 2 - 3 } & Sternal Fracture & $1(2 \%)$ \\
\cline { 2 - 3 } & Clavicular Fracture & $2(4 \%)$ \\
\cline { 2 - 3 } & Scapular Fracture & $3(6 \%)$ \\
\cline { 2 - 3 } & Dorsal Spine Fracture & $2(4 \%)$ \\
\cline { 2 - 3 } & Surgical emphysema & $15(30 \%)$ \\
\cline { 2 - 3 } & Chest Wall hematoma & $9(18 \%)$ \\
\hline \multirow{4}{*}{ Pleural Injuries } & $\begin{array}{l}\text { Pleural fluid collection } \\
\text { (hemothorax) }\end{array}$ & $21(42 \%)$ \\
\cline { 2 - 3 } & Simple pneumothorax & $7(14 \%)$ \\
\cline { 2 - 3 } & Tension pneumothorax & $3(6 \%)$ \\
\cline { 2 - 3 } & Hydro-pneumothorax & $5(10 \%)$ \\
\hline \multirow{4}{*}{ Lung Parenchymal Injuries } & Lung Contusion & $28(56 \%)$ \\
\cline { 2 - 3 } & Lung Laceration & $2(4 \%)$ \\
\hline \multirow{5}{*}{ Mediastinal Injuries } & $\begin{array}{l}\text { Pericardial collection } \\
\text { hemopericardium) }\end{array}$ & $3(6 \%)$ \\
\cline { 2 - 3 } & Pneumo-pericardium & $2(4 \%)$ \\
\cline { 2 - 3 } & Esophageal injuries & $0(0 \%)$ \\
\cline { 2 - 3 } & Pneumo-mediastinum & $5(10 \%)$ \\
\hline Tracheo-bronchial Injuries & & $1(2 \%)$ \\
\hline Diaphragmatic injuries & & $2(4 \%)$ \\
\hline
\end{tabular}




\section{DISCUSSION}

Out of the 50 patients in this study, 37 were males and 13 were females (ratio 2.5:1). Age of patients involved in this study was 2-75 years (average of 51.4 years) and most of patients were in the age group 21-50 years $(62 \%)$.

These result consistent with Dabees et al. (2014) who stated that $70 \%$ of patients exposed to blunt chest trauma are males. They also consistent with Dabees et al. (2014) who stated that $60 \%$ of patients in their study were in the age group 20-40 years.

In this study, motor vehicle accidents were the most common cause of trauma accounting for $58 \%$ of the cases. The second most common cause of injury in this study was fall from height, which occurred in $36 \%$ of the patients and this was consistent with Alborzi et al. (2016) who stated that most common causes of blunt chest trauma are road traffic accidents followed by fall from height and acts of violence are also relevant causes.

In this study, pulmonary contusions were the most common parenchymal lung injury detected. It was found in $56 \%$. This was accepted by Miele et al. (2016) who reported that pulmonary contusion is the most common lung injury from blunt chest trauma, with a prevalence of $17-$ $70 \%$ and chest MDCT is highly sensitive in identifying pulmonary contusion and may help in predicting the need for mechanical ventilation.

Parenchymal lung lacerations were found in 2 patients (4\%). MDCT scan is highly sensitive in detecting lung lacerations compared to poor sensitivity by chest radiography. This coincided with
Miele et al. (2016) who stated that pulmonary lacerations were considered as uncommon injury before the widespread use of MDCT in trauma patients as these were not frequently identified on chest radiographs.

In this study, hemothorax was detected in $42 \%$. These results coincided with Kaewlai et al. (2010) as he stated that hemothorax occurs in $30-50 \%$ of patients with blunt chest trauma.

Pneumothorax was detected in $20 \%$ simple pneumothorax in $14 \%$, tension pneumothorax in $6 \%$ and hydropneumothorax in $10 \%$. These results coincided with Nelson et al. (2013) as he stated that pneumothorax occurs in 30$40 \%$ of trauma patients.

In this study, rib fracture was detected in 18\%. However Dabees et al. (2014) stated that rib fractures are the most common type of injury after blunt chest trauma and occur in about $50 \%$ of the patients. In this study rib fractures were detected by $\mathrm{CT}$ in only in 28 patients (22.4\%). These results may be coincided with Ringl et al. (2015) who stated that detecting rib fractures in $\mathrm{CT}$ can be a quite challenging task.

Scapular factures were found in $6 \%$. This was in agreement with Wirth and Stephan (2016) who reported that fractures of the scapula are uncommon, accounting for $3-5 \%$ of all shoulder girdle fractures and occurring in $3.7 \%$ of patients with multiple injuries.

Clavicular fractures were found in $4 \%$. This coincided with Maier et al. (2011) who reported that clavicular fractures from blunt chest trauma account for 2.6$5 \%$ of all fractures. 
Sternal fractures were detected in $2 \%$. This coincided with Wirth and Stephan (2016) who stated that sternal fractures are rather seldom, appearing in 3-8\% of patients after severe blunt chest trauma and they always be interpreted as a sign of a large amount of energy having been transmitted to the chest wall and deeper structures, particularly in combination with a fracture of the scapulae.

Dorsal spine fractures were detected in $4 \%$. Those were at level of D12 vertebrae and coincided with Geyer and Linsenmaier (2016) who stated that the most vulnerable site is between the ninth and twelfth vertebra.

In this study, soft tissue chest wall hematoma was detected in $18 \%$ and in all cases it was related to rib fractures. This coincided with Chung et al. (2010) who stated that Soft tissue hematomas may occur during direct compression trauma when rib fractures cause laceration of veins or arteries.

Subcutaneous emphysema was found in $30 \%$. These findings were in agreement with João et al. (2014) who stated that subcutaneous emphysema is present in up to $34 \%$ after blunt chest trauma.

In this study, there were $10 \%$ with pneumo-mediastinum. This coincided with Oikonomou and Prassopoulos (2011) who stated that pneumo-mediastinum occurs in up to $10 \%$ of patients with blunt chest trauma.

Pneumopericardium was detected in 2 patients (4\%) this coincided with Mirka et al. (2012) as they stated pneumopericardium is a rare finding in blunt chest trauma. Hemopericardium was detected in $6 \%$. This coincided with João et al. (2014).

In this study, tracheobronchial injuries were detected in $2 \%$ on MDCT scan. This was in agreement with Scaglione et al. (2016) who reported that tracheobronchial injuries are rare in clinical practice because most patients die before arriving at the emergency department from either associated injuries to vital structures, hemorrhage, tension pneumothorax, or respiratory insufficiency or from an airway injury. In clinical series, blunt tracheobronchial trauma has been reported as accounting for $0.2-8 \%$ of all cases of blunt chest trauma.

In this study, diaphragmatic injury was detected in $4 \%$. This coincided with João et al. (2014) who stated that diaphragmatic rupture occurs in $0.8-7 \%$ of patients hospitalized with a blunt trauma. MDCT not only detects small diaphragmatic discontinuities, but also identifies the herniated fat or viscera.

\section{CONCLUSION}

The information provided by MDCT may lead to critical changes in patients' management; so that clinicians, radiologists, and radiology residents should be familiar with the different aspects of MDCT evaluation of this non negligible group of patients.

\section{REFERENCES}

1. Alborzi $Z$, Zangouri V, Paydar $S$, Ghahramani Z, Shafa $M$ and Ziaeian $B$. (2016): Diagnosing Myocardial Contusion after Blunt Chest Trauma. J Tehran Heart Cent, 11(2): 49-54.

2. Blyth A (2014): Thoracic trauma. BMJ, 348: 1137-9. 
3. Chung JH, Carr RB and Stern EJ (2010): Extrapleural hematomas: imaging appearance, classification, and clinical significance. J Thorac Imaging, 26:218-223.

4. Dabees NL, Salama AA, Abd Elhamid S and Sabry MM (2014): Multi-detector computed tomography imaging of blunt chest trauma. The Egyptian Journal of Radiology and Nuclear Medicine, 45(4): 1105-1113.

5. Davies RM, Scrimshire AB, Sweetman L, Anderton MJ and Holt EM (2016): A decision tool for whole-body CT in major trauma that safely reduces unnecessary scanning and associated radiation risks: an initial exploratory analysis. Injury, 47(1): 4349.

6. Geyer $L$ and Linsenmaier U (2016): MDCT of Chest Trauma. Schoepf UJ, Reiser MF (Eds.), Multidetector-Row CT Thorax (2nd ed.), Springer, Pp. 525-544

7. João APM, Mascarenhas V, Herédia V and Ramalho M (2014): Multi detector Computer Tomography: Evaluation of Blunt Chest Trauma in Adults. Radiology Research and Practice, 2014: 1-12.

8. Kaewlai LL, Asrani AV and Novelline RA (2010): Multidetector CT of blunt thoracic trauma. Radiographics, 28(6): 1555-1570.

9. Maier D, Jaeger M, Izadpanah $\mathbf{K}$, Bornebusch L and Südkamp NP (2011): Traumatic injuries of the sternoclavicular joint. Unfallchirurg, 114:611-621.

10. Miele V, Giampietro I, Ianniello S, Pinto F and Trinci $M$ (2016): Diagnostic imaging in pediatric polytrauma management. Radiol Med., 120(1): 33-49.
11. Mirka H, Ferda J and Baxa J. (2012): Multi detector computed tomography of chest trauma: indications, technique and interpretation. Insights Into Imaging, 3(5): 433449.

12. Nelson D, Porta C and Satterly S. (2013): Physiology and cardiovascular effect of severe tension pneumothorax in a porcine model. J Surg Res., 184(1): 450-457.

13. Oikonomou A and Prassopoulos P. (2011): CT imaging of blunt chest trauma. Insights Imaging, 2: 281-295.

14. Palas J, Matos AP, Mascarenhas V, Herédia V and Ramalho M. (2014): Multidetector computer tomography: evaluation of blunt chest trauma in adults. Radiol Res Pract., 2014:864369.

15. Ringl H, Lazar M, Topker M, Woitek R, Prosch H, Asenbaum U, Balassy C, Toth D, Weber M, Hajdu S, Soza G, Wimmer A and Mang T (2015): The ribs unfolded - a CT visualization algorithm for fast detection of rib fractures: effect on sensitivity and specifi city in trauma patients. Eur Radiol., 25:1865-1874.

16. Scaglione M, Ronza R, Rossi C, Martino MT, Grassi $R$ and Vaidya $S$ (2016): Emergency radiology of the chest and cardiovascular system. Scaglione M, Linsenmaier U, Schueller G, Berger F, Wirth S (Eds.). Springer, Switzerland, Pp. 25-60.

17. Wirth S and Stephan J (2016): Bony and Thoracic Chest Wall Injuries. Scaglione M, Linsenmaier U, Schueller G, Berger F, Wirth S (Eds.), Emergency radiology of the chest and cardiovascular system, Springer, Switzerland, Pp. 25-60. 
دور التصوير المقطعي في تقييم الصدمات الغير حادة للصدر أحمد أبوزيد متولي محمد جلال، عبدالنبى بيومى محمد، أحمد محمد عبدالغفار زيدان قسم الأشعة التثخيصية، كلية الطب، جامعة الأزهر

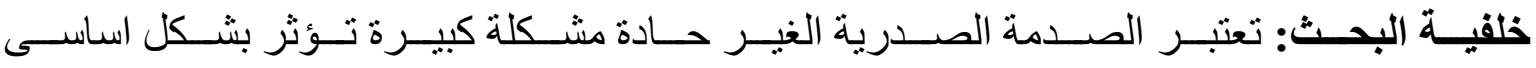

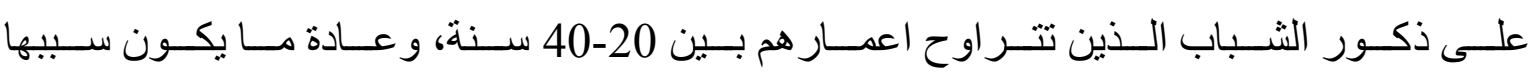

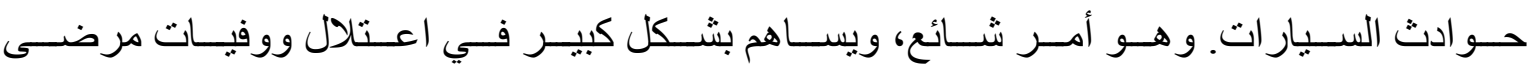

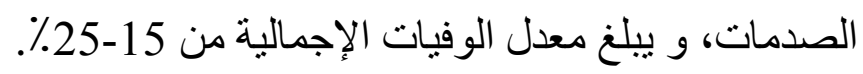

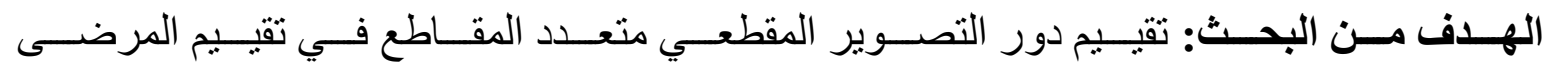
الذين يعانون من صدمة غير حادة في الصدر.

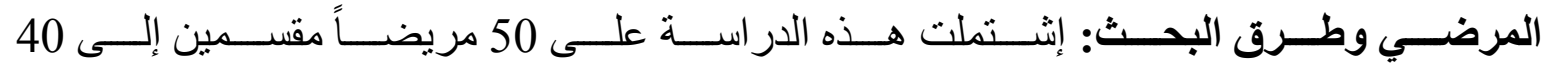

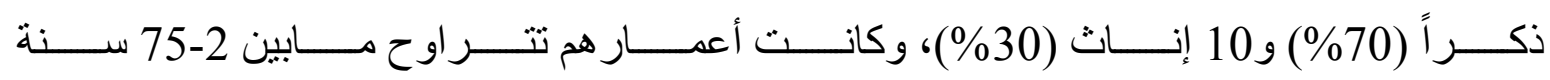

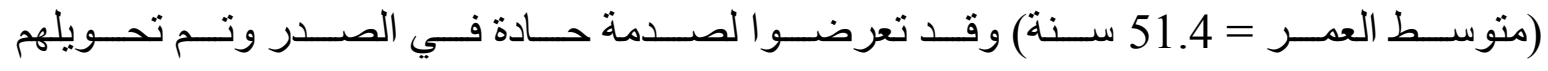

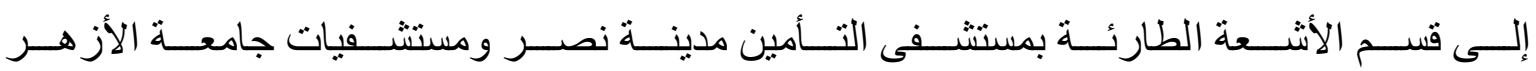

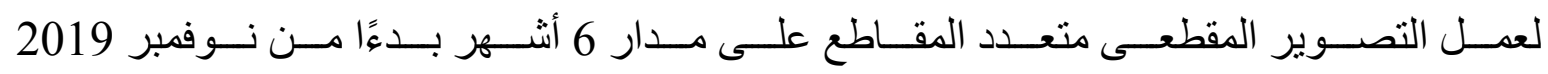

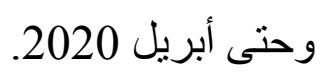

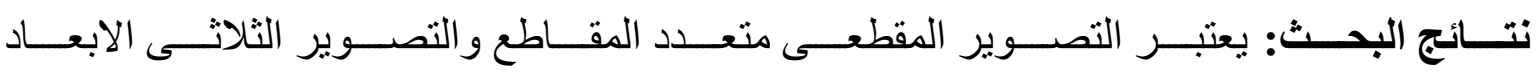

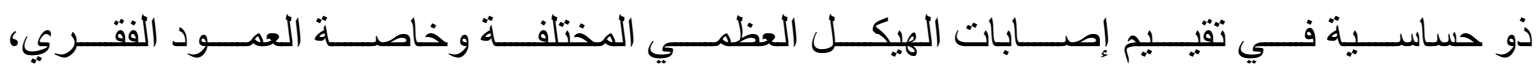

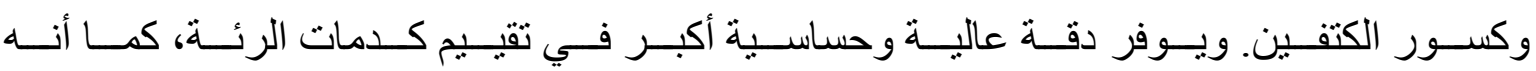

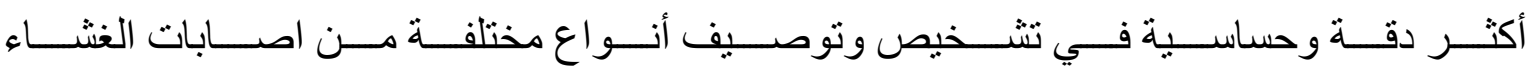

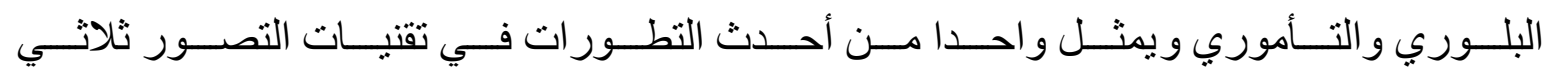
الأبعاد الذي يسمح لنقييم الثنب الهو ائية وصو لا إلى الجيل السادس و السابع.

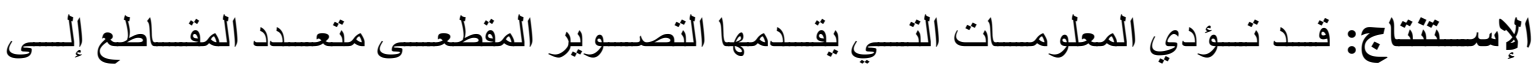

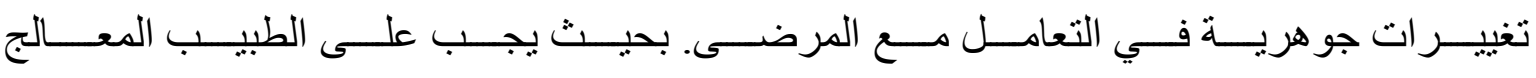

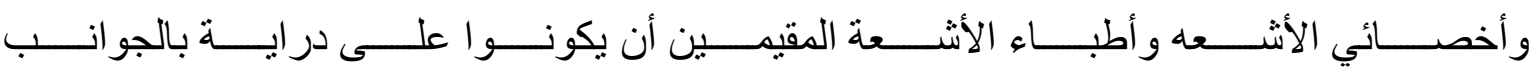
الدختلفة لتقييم التصوير الدقطعى متعدد المقاطع لهذه المجمو عة من المرضى. 